\title{
Detection of Toxoplasma gondii antibodies in trade donkeys (Equus asinus) at Ganawuri district market, Riyom Local Government Area, Plateau State, North Central Nigeria
}

\author{
Ishaku Bata Shalangwa and Shalom Byencit Kumra \\ Department of Animal Health, Federal College of Animal Health and Production Technology, National Veterinary Research \\ Institute, Vom, Nigeria. \\ Corresponding author: Ishaku Bata Shalangwa, e-mail: drsshalangwa2005@yahoo.co.uk \\ Co-author: SBK: yohananancwat1@gmail.com \\ Received: 08-02-2019, Accepted: 08-05-2019, Published online: 17-06-2019
}

doi: 10.14202/IJOH.2019.60-64 How to cite this article: Bata SI, Byencit SK. Detection of Toxoplasma gondii antibodies in trade donkeys (Equus asinus) at Ganawuri district market, Riyom Local Government Area, Plateau State, North Central Nigeria. Int J One Health 2019;5:60-64.

\begin{abstract}
Background and Aim: Toxoplasma gondii is a parasite of public health significance due to its possible transmission to humans through ingestion of tissue cysts in raw or undercooked meat or food or water contaminated with oocysts shed by felids and transplacental transmission. This study was carried out to provide information on the possible risk of transmission through eating undercooked donkey meat by conducting a market based cross-sectional study design to determine the presence of T. gondii antibodies in trade donkeys in Ganawuri district, Riyom Local Government Area, Plateau State, North Central, Nigeria.
\end{abstract}

Materials and Methods: One hundred and thirteen serum samples were collected from trade donkeys at the market and analyzed for $T$. gondii antibodies using latex agglutination test (LAT). Serum samples with LAT titer $>10 \mu 1 / \mathrm{ml}$ were considered positive.

Results: The distribution of the donkeys based on their sources showed that greater proportions $(61.1 \%)$ were from North Eastern part of the country. The study showed that 31 of the serum samples collected and analyzed were positive for T. gondii antibodies given an overall prevalence of $27.4 \%$. The prevalence ranges between 22.2 and $33.3 \%$ across the states where the donkeys were sourced. The study showed that seropositivity increases with age $(\mathrm{p}=0.003 ; \mathrm{OR}=11.8)$ and ranges between 12.5 and $47.2 \%$. The prevalence did not vary significantly based on sex and source/location $(p=0.494, O R=0.05$; $0.920,1.45$, respectively).

Conclusion: This study showed that trade donkeys at Ganawuri district market have antibodies to T. gondii and suggest a public health risk from the consumption of undercooked donkey meat.

Keywords: antibodies, cross-sectional, donkeys, prevalence, public health, Toxoplasma gondii, trade.

\section{Introduction}

Toxoplasma gondii is an obligate intracellular apicomplexan protozoan that can infect virtually all warm-blooded animals [1,2]. The parasite has been reported to have a worldwide distribution [3]. Felids, both domestic and wild are the only known definitive hosts. The parasite is of public health significance due to its possible transmission to humans through ingestion of tissue cysts in raw or undercooked meat or food or water contaminated with oocysts shed by felids and transplacental transmission [4,5]. It is also known to cause great economic losses in the livestock industry due to abortion, premature, and stillbirth. Infection with $T$. gondii in humans is usually asymptomatic; however, the infection may cause abortion in pregnant women or occasionally toxoplasmic encephalitis or

Copyright: Shalangwa and Kumra. This article is an open access article distributed under the terms of the Creative Commons Attribution 4.0 International License (http://creativecommons.org/ licenses/ by/4.0/), which permits unrestricted use, distribution, and reproduction in any medium, provided you give appropriate credit to the original author(s) and the source, provide a link to the Creative Commons license, and indicate if changes were made. The Creative Commons Public Domain Dedication waiver (http:// creativecommons.org/ publicdomain/zero/1.0/) applies to the data made available in this article, unless otherwise stated. even death in patients with an immune-suppression disease like AIDS $[1,6]$.

Aside from being useful to humans in sports competition, police work, carriage, donkeys, and horses serve as sources of protein and traditional delicacies in many parts of the world [7]. Infection of T. gondii in horses is usually subclinical, but there may be fever, ataxia, retinal degeneration, and abortion or stillbirth in pregnant equine. Even though infection with $T$. gondii is usually asymptomatic, viable parasites have been isolated from the meat of animals such as sheep, goat, cow, pig, chicken, horse, and donkey [8]. Meat from birds and warm-blooded animals traditionally has been considered major sources of T. gondii infection [9]. More so, cases of human toxoplasmosis associated with consumption of horse and donkey meat have been reported in some countries $[2,10]$.

At the moment donkeys are reared majorly on extensive management system with few managed intensively in this part of the country. These practices expose the animal to various infective stages of parasites (some of which are zoonotic) with attendant health impact. Donkeys are routinely brought to 
Ganawuri district market to be sold while some are slaughtered for human consumption. Data on T. gondii in trade donkeys in Ganawuri district market, Riyom Local Government Area, Plateau State, North Central Nigeria are scarce.

This study was carried out to provide information on the possible risk of transmission through eating undercooked donkey meat by conducting a market based cross-sectional study design to determine the presence of $T$. gondii antibodies in trade donkeys in Ganawuri district, Riyom Local Government Area, Plateau State, North Central, Nigeria.

\section{Materials and Methods}

\section{Ethical approval}

This study was approved by the Animal Health Department, Federal College of Animal Health and Production Technology, National Veterinary Research Institute Vom, Nigeria, before sample collection. Animals were handled in strict compliance with good animal practice.

\section{Study area}

The study was conducted in Ganawuri district, Riyom Local Government Area, Plateau State (Figure-1). It is located at an elevation of $1265 \mathrm{~m}$ above sea level. Its geographical coordinates are $9^{\circ} 41^{\circ} 0^{\prime \prime}$ North, $8^{\circ} 42^{\prime} 0^{\prime \prime}$ East. Riyom Local Government Area has an area of $807 \mathrm{~km}^{2}$ and a population of 131,557 at the 2006 census which is predominantly Berom. The Local Government Area has coordinates of $12^{\circ} 08^{\prime} 00^{\prime \prime} \mathrm{N}, 8^{\circ} 46^{\prime} 00^{\prime \prime} \mathrm{E}$. It shares boundaries with Kaduna and Nasarawa State. Ganawuri is the place where agricultural farming is practiced. Donkeys serve as a source of protein and income to the majority of the people in the area
(NIPOST, 2009). Donkeys were brought from the northeastern and northwestern part of the country on every market day.

\section{Study design}

A cross-sectional market-based study design was carried out while a systematic random sampling technique was adopted for the inclusion of animals into the study. Donkeys brought to the market were first tied to a stake. About 20-30 donkeys were brought from different parts of the country (mostly northeastern and northwestern part of the country) during each market day. In each market day, donkeys presented were assigned numbers, and those with even numbers were included in the study and for sample collections. Approximately 13-15 samples were collected per visit. Information on sex and source of donkey was recorded. The age of each donkey was estimated using dentition. The sample collection was between the months of December 2017 and April 2018

\section{Sample collection and handling}

Blood samples were collected from 113 donkeys. Samples were labeled and transported on ice to the Parasitology Laboratory, Federal College of Animal Health and Production Technology, National Veterinary Research Institute, Vom. Samples were centrifuged at $1000 \mathrm{rpm}$ for $3 \mathrm{~min}$ to separate serum. Serum was stored at $-20^{\circ} \mathrm{C}$ until used.

\section{Serology}

Antibodies to $T$. gondii were determined using the latex agglutination test (LAT) kits as described by the manufacturer (Biokit, Barcelona-Spain). A semi-quantitative analysis was carried out. Briefly, $50 \mu 1$ of normal saline was placed on slide sections

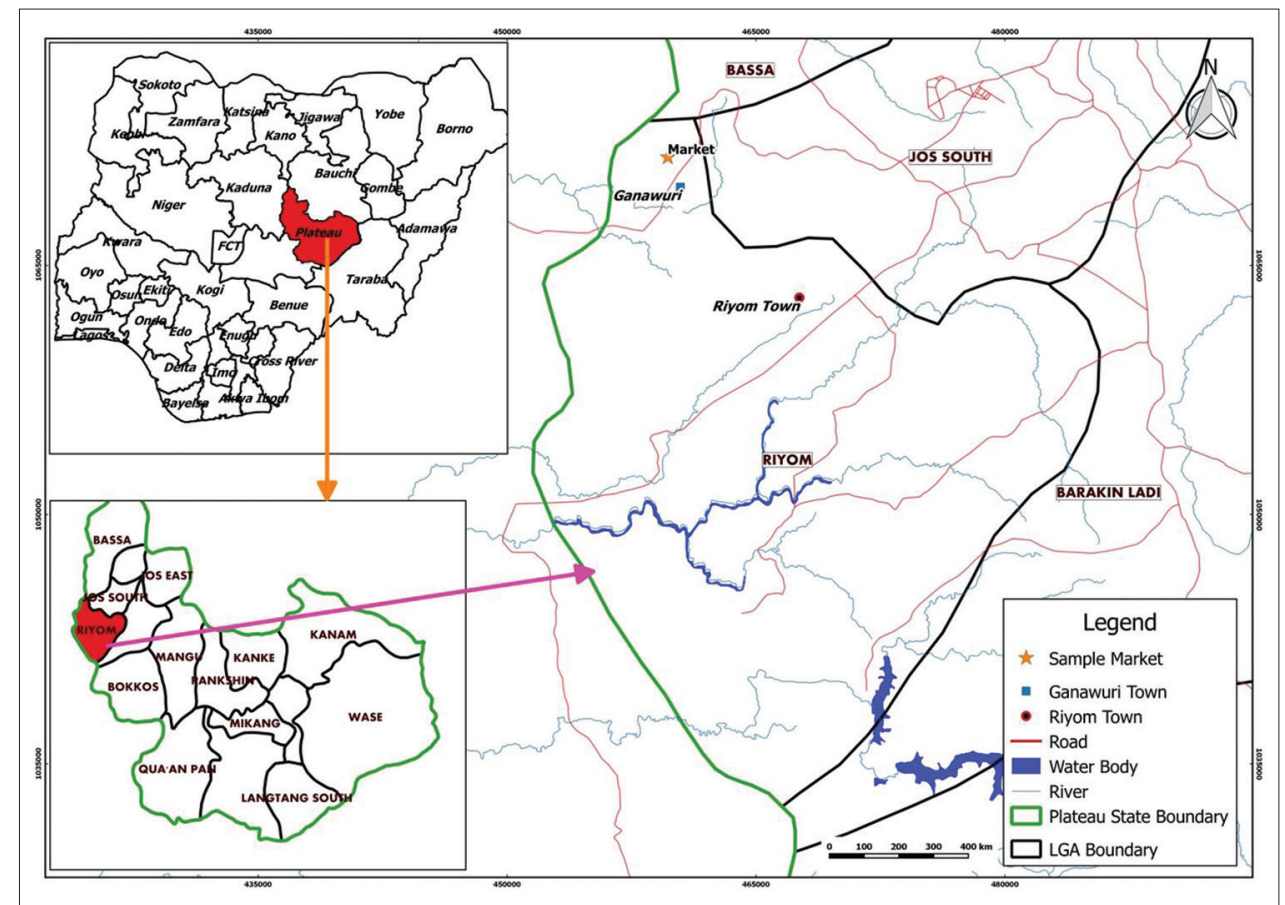

Figure-1: Map of Nigeria showing the study area. 
2 through 6. A $50 \mu 1$ of the sample was placed on slide sections 1 and 2 using an automatic pipette. The sample and the saline solution on section 2 were mixed several times, and $50 \mu \mathrm{l}$ of the mixture made on section 2 was transferred to section 3 and repeated through to section 6 , thereafter discarding $50 \mu \mathrm{l}$. One drop of reagent was then added and mixed with a stirrer covering the whole surface of the slide section. The slide was rotated for $5 \mathrm{~min}$ on a rotary shaker set at $80-100 \mathrm{rpm}$. The presence of agglutination at titer $>10 \mu \mathrm{l} / \mathrm{ml}$ was considered positive. Positive and negative controls were included in each test.

\section{Statistical analysis}

Data obtained were analyzed using statistical package for the social sciences (SPSS) version 21(IBM Corp. USA). For categorical data, Chi-square test was used to determine the association between the presence of $T$. gondii antibodies and factors such as age, sex, and source of trade donkeys in Ganawuri district market. $\mathrm{p}<0.05$ was considered statistically significant.

\section{Results}

The study showed that greater proportions $(61.1 \%)$ of the donkeys at Ganawuri market were from Northeastern part of the country(Figure-2). Of the 113 serum samples collected from donkeys, 31 were positive for $T$. gondii antibodies using LAT kit giving an overall prevalence of $27.4 \%$ (Table-1). The result showed that the seroprevalence was higher $(29.0 \%)$ in male than in female $(26.8 \%)$; though not statistical significant $(\mathrm{p}=0.494, \mathrm{df}=1, \mathrm{OR}=0.05)$ (Table-2). More so, the result showed that $T$. gondii seropositivity increases with age $(\mathrm{p}=0.003, \mathrm{OR}=11.8)$ and ranges between 12.5 and $47.2 \%$ (Table-3). There was no statistically significant difference between $T$. gondii seropositivity and the sources of the donkeys. The seroprevalence however based on the sources of donkeys ranges between 21.4 and $31.8 \%$ with Yobe, Bauchi, Kaduna, Maiduguri, Kano, and Gombe state having a prevalence of 21.4, 22.2, 22.7, 31.2\%, 31.8 , and $33.3 \%$, respectively $(\mathrm{p}=0.920$; OR 1.45$)$ (Figure-3).

\section{Discussion}

Ganawuri district market is a major market in North Central Nigeria where donkeys are sold and or slaughtered for human consumption. This study was, therefore, carried out to determine the prevalence of $T$. gondii antibodies in trade donkeys to ascertain their role in the transmission of the parasite. Studies

Table-1: Overall prevalence of $T$. gondii antibodies in trade donkeys in Ganawuri district market.

\begin{tabular}{lcc}
\hline $\begin{array}{l}\text { No. of samples } \\
\text { collected }\end{array}$ & No. of positive & $\%$ prevalence \\
\hline 113 & 31 & 27.4 \\
\hline$T$
\end{tabular}

carried out by Bártová et al. [11] reported a prevalence of $17.0 \%$ in donkeys sourced from Bauchi State, Nigeria. Studies conducted in Egypt (Monofia Province) reported a prevalence of $25.6 \%$ [12] while prevalence of 25.6, 23.6, and 20.3\% were reported in Spain, Northeastern, and Southwestern China, respectively [5,13,14]. Similarly, Machacova et al. [15] reported a seroprevalence of 5 and $8 \%$ using LAT and IFAT, respectively, in donkeys in Italy while AlvaradoEsquivel et al. [16] reported a prevalence of $10.9 \%$ in donkeys slaughtered for human consumption in Mexico. The seroprevalence of $T$. gondii in donkeys in the study area is comparatively higher than those in other regions. Consumption of undercooked donkey meat may pose a possible health risk to humans in the area. The differences in the hygienic conditions, management practices, climatic conditions, and cat abundance may explain the differences in the seroprevalence reported in the different regions/areas with the present study. More so, differences in the sensitivity of the serological test and sample size may account for the variation in the seroprevalence in different studies. The limitation of our study is that the validity of LAT kits for use in animals is unknown and needs to be put into account while interpreting our findings.

Studies in some species of animals showed that T. gondii seropositivity increases with age $[17,18]$. This study has revealed that $T$. gondii seropositivity

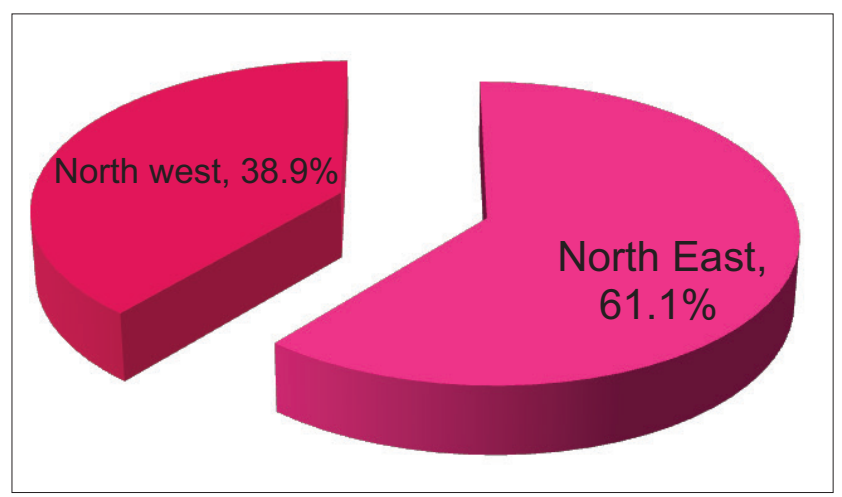

Figure-2: Sources of donkeys at Ganawuri market.

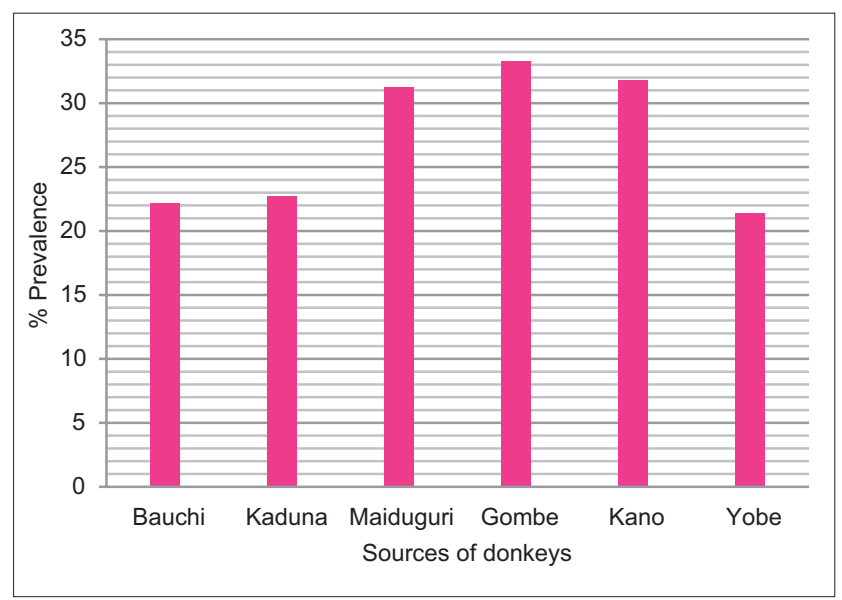

Figure-3: Seroprevalence of $T$. gondii in trade donkeys at Ganawuri district based on the source. 
Table-2: Seroprevalence of T. gondii in trade donkeys in Ganawuri district market based on sex.

\begin{tabular}{lccccc}
\hline Sex & No. examined & No. of positive & \% prevalence & p-value & OR \\
\hline Male & 31 & 9 & 29.0 & 0.494 & 0.05 \\
Female & 82 & 22 & 26.8 & & \\
Total & 113 & 31 & & & \\
\hline
\end{tabular}

T. gondii=Toxoplasma gondii

Table-3: Seroprevalence of T. gondii in trade donkeys at Ganawuri district market based on age.

\begin{tabular}{lccccc}
\hline Age (years) & No. examined & No. of positive & \% prevalence & p-value & OR \\
\hline $4-6$ & 40 & 5 & 12.5 & \\
$<6 \leq 10$ & 37 & 9 & 24.3 & 0.003 & 11.8 \\
$>10$ & 36 & 17 & 47.2 & & \\
\hline
\end{tabular}

T. gondii=Toxoplasma gondii

differs significantly among the age group examined. Increased in age usually, portents increase in contact period of an animal with the contaminated environment [18]. This may explain the reason for the higher prevalence in those older than 10 years. Miao et al. [5], in contrast, reported no significant difference between the age group examined in their study. The seropositivity of $T$. gondii in donkeys did not differ significantly in relation to sex and source. This is in agreement with the report of Miao et al. [5] who reported a lack of significant difference in relation to sex and location or sources of donkeys in a study conducted in Southwestern China. This may suggest that both male and female donkeys have equal chances of being exposed to the parasite. In contrast, El-Ghaysh et al. [12] and Machacova et al. [15] in their studies reported a higher prevalence in females than in males.

Greater proportions of the donkeys sold at Ganawuri district market for slaughter were from the Northeastern part of the country. T. gondii seropositivity in donkeys in this study did not vary according to the source of the donkeys, although the prevalence rate differs with reports from other parts of the world. Similarities in the vegetation, climatic condition, cat abundance, and management practices in these areas (Northeastern and Northwestern part of Nigeria) where the donkeys were sourced might be the reason for lack of significant differences in the seropositivity.

\section{Conclusion and Recommendations}

This study revealed a relatively high prevalence of $T$. gondii in trade donkeys in Ganawuri district market, Riyom Local Government Area compared to those reported in other regions. The seropositivity increased with age of donkey and did not differ according to sex and source. Undercooked donkey meat in the area may represent a potential health risk for humans. Donkey meat should, therefore, be properly cooked before consumption. Proper washing of hands by meat handlers is also recommended. The impact of $T$. gondii on the productivity of donkeys in the area should be investigated while studies should be carried out to determine the seroepidemiology of the parasite in a larger sample population of donkeys and other species of animals. An attempt should also be made to isolate $T$. gondii cysts in the tissues of donkeys using bioassay to ascertain the presence of viable tissue cysts. More so, the strains circulating in the area should be identified.

\section{Authors' Contributions}

IBS conceived and designed the study. IBS and SBK developed the project. SBK collected the samples. SBK and IBS carried out the serology and SBK produced the tables. SBK and IBS wrote the draft of the article. IBS carried out the data analysis. Both authors read and approved the final draft of the manuscript.

\section{Acknowledgments}

The authors appreciate the staff of Ganawuri market slaughter slab for their support and cooperation during the sample collection. We thank the staff of the Parasitology and Clinic-side Laboratory of the Federal College of Animal Health and Production Technology, National Veterinary Research Institute, Vom, for their assistance in the separation of serum and providing a facility for the serology. The authors did not receive any fund for this study.

\section{Competing Interests}

The authors declare that they have no competing interests.

\section{Publisher's Note}

Veterinary World (Publisher of International Journal of One Health) remains neutral with regard to jurisdictional claims in published map and institutional affiliation.

\section{References}

1. Zhou PZ, Chen HI, Li HS, Zheng R, Lin Q, Zoul F. Principles and Practice of Infectious Diseases. $6^{\text {th }}$ ed. Philadelphia, PA: Churchill Livingstone, an Imprint of Elsevier; 2005.

2. Chen J, Xu MJ, Zhou DH, Song HQ, Wang CR, Zhu XQ, et al. Canine and feline parasitic zoonoses in China. Parasit Vectors 2012;5:152.

3. Tenter AM, Heckeroth AR, Weiss LM. Toxoplasma gondii: From animals to humans. Int J Parasitol 2000;30:1217-58. 
4. Dubey JP. History of the discovery of the life cycle of Toxoplasma gondii. Int J Parasitol 2009;39:877-82.

5. Miao Q, Wang X, She LN, Fan YT, Yuan FZ, Yang JF, et al. Seroprevalence of Toxoplasma gondii in horses and donkeys in Yunnan Province, Southwestern China. Parasit Vectors 2013;6:168.

6. Hill DE, Dubey JP. Toxoplasma gondii prevalence in farm animals in the United States. Int J Parasitol 2013;43:107-13.

7. Miao Q, Huang SY, Qin SY, Yu X, Yang Y, Yang JF, et al. Genetic characterization of Toxoplasma gondii in Yunnan black goats (Capra hircus) in Southwest China by PCR-RFLP. Parasit Vectors 2015;8:57.

8. Dubey JP. Toxoplasma gondii infections in chickens (Gallus domesticus): Prevalence, clinical disease, diagnosis and public health significance. Zoonoses Public Health 2010;57:60-73.

9. Kijlstra A, Jongert E. Control of the risk of human toxoplasmosis transmitted by meat. Int J Parasitol 2008;38:1359-70.

10. Dubey JP, Thulliez P, Romand S, Kwok OC, Shen SK, Gamble HR, et al. Serologic prevalence of Toxoplasma gondii in horses slaughtered for food in North America. Vet Parasitol 1999;86:235-8.

11. Bártová E, Sedlák K, Kobédová $\mathrm{K}$, Budíková $\mathrm{M}$, Atuman YJ, Kamani J, et al. Seroprevalence and risk factors of Neospora spp. and Toxoplasma gondii infections among horses and donkeys in Nigeria, West Africa. Acta Parasitol
2017;62:606-9.

12. El-Ghaysh A. Seroprevalence of Toxoplasma gondii in Egyptian donkeys using ELISA. Vet Parasitol 1998;80:71-3.

13. García-Bocanegra I, Cabezón O, Arenas-Montes A, Carbonero A, Dubey JP, Perea A, et al. Seroprevalence of Toxoplasma gondii in equids from Southern Spain. Parasitol Int 2012;61:421-4.

14. Yang N, Yuan G, Zhang G, Li H, He J. Seroprevalence of Toxoplasma gondii in slaughtered donkeys and horses Liaoning province Northeastern China. Parasit Vectors 2013;6:140.

15. Machacova T, Bartova E, Di Loria A, Sedlak K, Mariani U, Fusco G, et al. Seroprevalence of Toxoplasma gondii in donkeys (Equus asinus) in Italy. J Vet Med Sci 2014; 76:265-7.

16. Alvarado-Esquivel C, Alvarado-Esquivel D, Dubey JP. Prevalence of Toxoplasma gondii antibodies in domestic donkeys (Equus asinus) in Durango, Mexico slaughtered for human consumption. BMC Vet Res 2015;11:6.

17. Dubey JP, Brown CA, Carpenter JL, Moore JJ $3^{\text {rd }}$. Fatal toxoplasmosis in domestic rabbits in the USA. Vet Parasitol 1992;44:305-9.

18. Bata SI, Maimadu A, Dakwang N, Renkat J, Olabode M. Seroprevalence and risk factors for Toxoplasma gondii in pigs, sheep and goats at slaughter in Jos municipal abattoir, Nigeria. Vet Sci Res Rev 2018;4:55-61. 